\title{
A terra da Mãe de Deus
}

\section{The land of the Mother of God}

\author{
Marly de A.G.Vianna \\ Professora do Programa de Mestrado em História do Brasil/Universidade Salgado de Oliveira \\ magvianna@uol.com.br
}

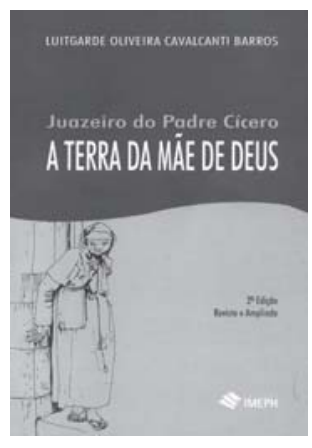

BARROS, Luitgarde Oliveira Cavalcanti. Juazeiro do Padre Cícero: a terra da Mãe de Deus. Fortaleza: Editora Imeph. 2008. $378 \mathrm{p}$.
$\mathrm{E}^{\mathrm{n}}$ m muito boa hora foi reeditado o livro de Luitgarde Oliveira Cavalcanti Barros, Juazeiro do Padre Cícero: a terra da Mãe de Deus. Especialista no assunto e notável pesquisadora, Luitgarde trabalhou - além de esgotar a bibliografia pertinente - com fontes inéditas e ainda com literatura de cordel, tornando o livro indispensável para os que estudam o Nordeste, a política regional, movimentos sociais, questões religiosas, entre outros temas. Além de ter uma abordagem teórica consistente, a autora, por ser nordestina, conhece bem a região, a vida da gente do Nordeste, suas carências, esperanças e lutas. Antropóloga, faz uma antropologia histórica, tratando ainda de aspectos econômicos, políticos e sociais, o que torna seu livro realmente interdisciplinar. Também é importante a reedição de um livro que fala do interior nordestino, das lutas, contradições e religiosidade de seu povo justamente aos setenta anos do assassinato de Lampião. ${ }^{1}$

Luitgarde tem uma abordagem original e instigante do fenômeno do Juazeiro, discutindo sobre o tema com conhecidos especialistas como Ralf Della Cava e Otacílio Anselmo. Baseando-se teoricamente em Gramsci, Luitgarde esclarece logo no início do livro que, para reconstituir historicamente a formação social do Ceará, partiu da ideia do filósofo italiano de que "tanto o passado histórico como as relações sociais existentes constituem as condições objetivas cujo reconhecimento é obra do sujeito histórico ativo (vontade coletiva em Gramsci)" (p.34).

O problema central do trabalho - o Juazeiro do Padre Cícero - insere-se, no dizer da autora, no tipo de organização religiosa da região. Utilizando os conceitos de estrutura e superestrutura, Luitgarde vê o fenômeno religioso como manifestação ideológica, sem isolálo no entanto na superestrutura. Relaciona estrutura e superestrutura sem privilegiar uma em relação à outra, embora considere que uma pode predominar conforme a situação histórico-social. No caso, sobre a instância dominante no bloco histórico da região estudada, o interior cearense, Luitgarde diz que é a superestrutura ideológica, especificamente a religião católica, a prevalecer.

\footnotetext{
${ }^{1}$ Ver,da mesma autora, a recente reedição, revista e ampliada, de A derradeira gesta: Lampião e nazarenos guerreando no sertão, Rio de Janeiro Mauad. 2007, cuja 1a edição é de 2000.
} 
A autora considera a religião como uma ideologia de classe, e trata o fenômeno de Juazeiro como movimento social, entendendo este como manifestação de luta de classes. Para Luitgarde, "a ideologia religiosa das populações do Nordeste é orgânica, na medida em que faz parte da estrutura social desde sua origem, sem perder a importância, ao contrário, na conjuntura analisada. Enquanto orgânico, o ato religioso sempre permaneceu necessário à estrutura social" (p.35).

A partir dessas considerações, abre-se uma discussão bastante profícua no estudo das ideologias populares. Usando mais uma vez conceitos gramscianos, a autora considera que os beatos de Juazeiro podem ser vistos como intelectuais orgânicos. O Padre Cícero Romão Batista, como sacerdote da Igreja Católica, comporta-se como um intelectual tradicional; ao mesmo tempo, ao opor-se a Igreja, assume o papel de intelectual orgânico de seus beatos. Mas se deve levar em conta que sua atitude no conflito com a Igreja é uma forma incompleta, atenuada, da consciência das camadas dominadas.

Quanto aos beatos, a autora os considera intelectuais orgânicos porque os vê como produtores de ideologia, representantes das camadas subalternas, cuja visão de mundo organizam não só no aspecto religioso, mas numa práxis que os leva a defender suas crenças. Os beatos atuam como produtores da ideologia que a consciência historicamente determinada pôde produzir naquela situação do Nordeste sertanejo, a ideologia possível de ser elaborada pela/para as camadas dominadas.

Justificando a afirmação de que os beatos seriam intelectuais orgânicos das classes subalternas do sertão cearense, Luitgarde diz que, por estarem diretamente ligados à produção material, suas práxis os transformaram em intelectuais. Como criadores de ideologia, uma ideologia dominante reinterpretada por eles, os beatos acabam por se opor à sociedade existente e lutam contra ela: contra a hierarquia da Igreja e contra os militares. Apoiando-se novamente em Gramsci, Luitgarde considera que, com isso, os beatos se opõem justamente às categorias sociais que representam os intelectuais tradicionais - os sacerdotes e militares.

Para a autora, a filosofia é uma ideologia das camadas intelectualmente superiores que possui unidade e coerência próprias. No entanto, unidade e coerência faltam aos grupos subalternos estudados, os beatos. Estão ausentes também em outros níveis da ideologia, como o senso comum, a religião e o folclore. Luitgarde explica essa falta de homogeneidade pelo fato de a ideologia permear grupos socialmente heterogêneos. Nesse caso, o senso comum e a religião serão as concepções de mundo mais difundidas.

O livro começa analisando o ambiente que propiciou o surgimento de uma "terra da Mãe de Deus", tanto a estrutura econômico-social do Ceará da época quanto sua organização religiosa, em especial a que tornou possível o aparecimento de figuras como a do padre Ibiapina, misto de religioso e militante social. A formação do Ceará sertanejo e a história das secas na região, sobretudo a de 1877 , são destaque no livro, para que se possa entender melhor o surgimento de Juazeiro.

No primeiro capítulo, Luitgarde interliga a organização religiosa e a estrutura social. Vendo a religião como forma específica de ideologia, considera a ideologia como parte da estrutura social, uma forma de relação social que é também, no caso de Juazeiro, uma relação de classe. 
O capítulo dois é dedicado à religião sertaneja. A autora analisa como concepção de mundo, sugere categorias do catolicismo popular e estuda a questão religiosa na sedição do Juazeiro. Mostra como, mediando ideologicamente o universo do sertão nordestino, o código simbólico, a mensagem presente no pensamento do homem sertanejo é a mensagem cristã. Foi essa mensagem que Antônio Conselheiro e o beato Lourenço transformaram numa concepção prática de vida cristã. Na segunda parte do capítulo, Luitgarde discute as categorias do catolicismo popular, o significado que os sertanejos davam ao 'ser santo', a relação entre santidade e o que pregava o Evangelho. Santo era o 'padrinho', um segundo pai, imagem ligada à vida do povo sertanejo, identificada à pobreza, humildade, mansidão; santos eram os conselhos e a fé na bondade e no arrependimento dos homens.

A sedição dos beatos mostra sua disposição em defender a sua terra, "a Terra da Mãe de Deus", que os acolhe, ampara, protege. A essência da questão religiosa de Juazeiro é vista, por Luitgarde, não como aparece, causada pelo milagre do surgimento do sangue de Cristo na hóstia recebida pela beata Maria Araújo, mas sim como uma luta, na Igreja, entre duas concepções do religioso, uma luta entre a hierarquia burocrática da Igreja e a religião como era vivida pelas classes subalternas.

Diferentemente dos que viram o fenômeno dos beatos de Juazeiro privilegiando o fator político, uns, e o religioso, outros, Luitgarde procurou integrá-los e relacioná-los com a história do sertão nordestino. Apresenta o aparecimento e a crescente influência política de Floro Bartolomeu sobre Padre Cícero como uma nova etapa na história de Juazeiro, encerrando a fase de coerência católica, época em que o religioso só tinha como apoio um padre suspenso das ordens, como ele, e o beato e intelectual José Marrocos. Nenhum dos dois seria capaz de enfrentar as forças da repressão que ameaçavam a Terra da Mãe de Deus.

Concordando ou discordando de algumas das teses do livro, ele reabre a discussão num nível bastante elevado, trazendo elementos indispensáveis à sua melhor compreensão. Tem o mérito de, ao lado da seriedade científica, ser um livro apaixonado, de quem conseguiu compreender, 'de dentro', a bravura e, ao mesmo tempo, a ingenuidade dos beatos na busca da construção de uma sociedade que os considerasse seres humanos e lhes tratassem com respeito. Luitgarde consegue mostrar o que há de comovente na luta dos sertanejos e beatos pela construção de sua dignidade. Os beatos tinham contra eles os grandes oligarcas que mandavam no sertão e a alta hierarquia de uma Igreja cuja romanização, segundo a autora, a contrapunha aos beatos.

Há muito tempo o povinho das brenhas se encontrava sem um guia. Desde a morte de Ibiapina, em 1883, ninguém mais varava os cafundós do mundo procurando os esquecidos da sorte para uma palavra de consolo e esperança. Mas agora eles tinham para onde ir! Enquanto em quase todas as paróquias a policia era chamada para dissolver grupos de penitentes, beatos eram corridos dos lugares por padres obedientes a seus bispos, no Juazeiro um homem era perseguido porque não queria largar seu povo sofredor que só tinha a ele por amigo e guia. Quanto mais se procurava, pela persuasão e pela força, erradicar aquela quase autonomia dos beatos e dos romeiros, mais estes se apegavam a seu padrinho, se confirmavam na crença de sua santidade. O catolicismo popular se afirmava na marcha dos desvalidos em busca de seus santos (p.246).

É um livro indispensável! 